\title{
Portugal sumiu do mapa!: do labirintismo em Gonçalo M. Tavares
}

\author{
Portugal disappeared from the map!: the labyrinth in Gonçalo M. Tavares
}

\author{
ISADORA DUTRA \\ Universidade Tuiuti do Paraná - Curitiba - Paraná - Brasil
}

-

\begin{abstract}
Resumo: O artigo descreve a construção e o efeito do espaço monstruoso na narrativa de Matteo perdeu o emprego, do escritor lusófono Gonçalo Tavares. A escrita errante do autor funciona como mapeamento de comportamentos humanos na cidade de aspecto labiríntico e sem marcas culturais. Na cidade disforme e monstruosa, proliferam as mais variadas obsessões e absurdos. Estas revelam a monstruosidade do humano sob o efeito do labirintismo que produz uma existência em constante estado de perdição. Para além do espaço da cidade, a própria escrita significa o espaço derradeiro do pensamento, numa cartografia de ideias.
\end{abstract}

Palavras-chave: Literatura portuguesa; Espaço; Labirinto; Identidade

\begin{abstract}
The article describes the construction and the effect of the monstrous space in the story Matteo Perdeu o Emprego, by the lusophone writer Gonçalo Tavares. The author's wandering writing works as a mapping of human behaviors in the city of labyrinthyne aspect and no cultural traits. In the monstrous and misshapen city ploriferate the most varied obsessions and absurds. These reveal the human's monstruosity under the labyrinthine effect that produces an existence in constant state of loss. Apart from the city space, the writing itselg means the ultimate space of thought, in a cartografy of ideas.
\end{abstract}

Keywords: Portuguese Literature; Space; Labyrinth; Identity

Navegações, colonizações e, depois, revoluções e descolonizações, além da questão da identidade permeando todos os topos literários, são temas fundamentais da Literatura Portuguesa de diferentes momentos históricos, ou seja, a produção literária estabelece suas bases no tripé história, memória e identidade. No entanto, a obra de Gonçalo Tavares, autor que começa a publicar no início dos anos 2000 e, em pouco mais de uma década, apresenta mais de trinta livros, propõe um desvio temático em relação à tradição, pelo menos no que diz respeito a navegações e etc. Permanece o interesse pela identidade, porém, não mais pelo viés nacional, mas pela perspectiva do indivíduo que circula pelas ruas da metrópole qualquer contemporânea. $\mathrm{O}$ mar, de modo geral, foi substituído pela cidade; a nação, pelo indivíduo.

A obra do autor estabelece o diálogo com a tradição literária em outras bases, a partir do jogo entre leitura e escrita em que a segunda transforma a primeira. A inserção intertextual de referências canônicas desencadeia o dialogismo de ideias que é a marca principal da sua relação com a tradição, num contexto textual de desestabilização de gêneros, formas e sentidos. Circulam pelo espaço ficcional, sob forma de personagem, por exemplo, figuras referenciais que fazem parte do processo de recriação do cânone, com um fundo de ironia.

Em relação à questão identitária, Gonçalo Tavares não está preocupado com a identidade do homem português e sim, segundo o próprio autor afirma em entrevistas, com a identidade do homem. O que interessa na sua narrativa é a "investigação de comportamentos humanos", com suas loucuras, obsessões e (não) sentidos. As imagens, míticas ou históricas, de Portugal já não fazem parte do cenário monstruoso no qual circulam suas personagens de comportamentos estranhos. Na cartografia urbana do autor já não está Portugal: sumiu do mapa! Aliás, não há mapas. O homem animalesco e/ou maquinal de Gonçalo Tavares existe em estado permanente de perdição, vivendo na errância de si mesmo.

A ideia de perdição é referida na segunda parte do livro Matteo perdeu o emprego, a qual insere o discurso 
ensaístico na obra na forma de posfácio ${ }^{1}$. Na nota de número 32 das reflexões finais, as quais teorizam acerca da organização, ideias e imagens contidas na primeira parte, ficcional, o autor remete à obra de Ernst Jünger para pensar a respeito do "sentimento de segurança" em meio ao perigo: "Os protagonistas, no meio do caos e da destruição, tentam orientar-se na floresta (símbolo do desorganizado e do confuso) através do conhecimento que têm das flores (...)" (TAVARES, 2013, p. 153).

A partir da identificação do conhecimento como elemento orientador em meio ao "caos" e "terror", ele busca reconhecer, na sucessão de ligações entre personagens e cenas que constituem a narrativa sobre Matteo, o "ponto de apoio". Acaba por apontar a letra $\mathrm{M}$ de Matteo e o personagem do título como referencial na estrutura do texto: "Tudo aponta para ali, tudo avança na sua direção; quando uma letra está perdida levanta a cabeça e vê o M, de Matteo, e assim percebe que está no bom caminho." (2013, p. 154). Ou seja, a ordem possível na narrativa de Matteo é a aleatória combinação do alfabeto.

O conhecimento orientador dos personagens de Jünger na floresta já não serve de farol no universo absurdo de Tavares, em consonância com o ambiente instável da modernidade líquida de que fala Zygmunt Bauman (2004). Se não há distinção, diz o sociológo polonês, entre o regular e o contingente, o aprendizado está impossibilitado de acontecer. Justamente a característica da contemporaneidade é ter eliminado tal distinção pelo domínio da instabilidade que força a não fixação de referências indispensáveis ao aprendizado. Portanto, o conhecimento do mundo social tende a ser igualmente instável em função de sua transitoriedade. Qualquer estratégia de vida, neste cenário, está fadada à esclerose.

O aprendizado diz respeito, no pensamento do teórico, à aquisição de habilidades, na forma de hábitos úteis, para a ação. A fixação do conhecimento em hábito é impossibilitada pela velocidade com que tudo se transforma nas relações sociais da vida líquida: "em que as condições sob as quais agem seus membros mudam num tempo mais curto do que aquele necessário para a consolidação, em hábitos e rotinas, das formas de

\footnotetext{
O dialogismo entre ensaio e ficção é características de toda obra de Gonçalo M. Tavares, numa desconstrução das barreiras entre gêneros discursivos, que é também um modo de dialogar com a tradição literária, filosófica e científica. Em Matteo perdeu o emprego, é antes mais fácil indicar a obra pela mídia, o livro, do que aceitar de imediato a classificação no gênero romance (termo que, aliás, não aparece nas apresentações paratextuais, em que é mencionado o "livro", a "ficção" e o "texto), já que esta funciona também como compilação de contos independentes que se tocam ou, pensando na imagem labiríntica a qual o livro está associado, "pontos"que possuem entre si trajetórias que se cruzam. Por isso, o Livro de G. Tavares existe na confusão dos gêneros.
}

agir" (BAUMAN, 2009, p. 7). O contexto muda antes que se possa de fato aprender sobre ele, de modo que as capacidades tornam-se obsoletas. O conhecimento é circunstancial e as projeções improváveis. A experiência já não constrói aprendizado e a ação exige contínua reinauguração, errante em vez de planejada ou construída com base no conhecimento adquirido da prática.

No amor líquido, por exemplo, dominado pelos padrões da linguagem da conectividade (conectar/ desconectar em vez de relacionar, tendo os dois termos da linguagem de rede exatamente a mesma importância) e das relações virtuais, é preciso antes estar em movimento e em alta velocidade do que manter elos duradouros. Pelo contrário, os elos precisam ser frouxos para serem facilmente desfeitos quando as mudanças do contexto exigirem. Acontece com o amor o mesmo processo que domina todos setores da vida líquida, do material ao afetivo, a mercantilização, ou marketização como diz Bauman (2009), pela expansão da lógica do consumo. Tudo é produto e segue o sistema de trocas monetárias. Também a felicidade é mercadoria na prateleira dos mercados, igualada ao consumo de objetos e serviços. Todas as relações são estabelecidas como relações de consumo em que a ênfase está em substituir como forma de atualizar e não sucumbir à morte por obsolescência. Apenas o estado de transitoriedade, afirma o autor, tem qualidade de permanente.

Tal fragilidade dos vínculos entre os indivíduos é um dos motivadores do sentimento de insegurança que faz parte da vida líquido-moderna. A experiência contemporânea está associada à "ausência de conforto existencial" (BAUMAN, 2009). Diante da instabilidade de todos os pontos de referência em relação aos quais se estabelecem as expectativas de vida, as ações cotidianas tendem a produzir um certo senso de desordem, o qual se tenta camuflar com a aparência de segurança. A insegurança e o medo são dois outros sentimentos da vida líquida que também fazem parte da lógica de mercado, gerando indústrias que ao mesmo tempo alimentam e se sustentam de ambos. O sistema econômico exige a abertura e expansão de novos mercados e a aparência de segurança participa como mais um produto de consumo, sendo a lógica da cidade pautada pela dicotomia segurança/insegurança.

Na modernidade líquida, a sociedade é constituída antes de mais nada de consumidores (aqueles que não entram ou não mantêm-se na roda do consumo são excluídos do sistema). Todos os momentos da vida humana como a maternidade, a infância, etc, ou sentimentos como a felicidade, o medo, etc, assumem conotações mercadológicas e tornam-se produtos. A vida líquida é uma vida de consumo. "A política de vida, (...), 
assim como a natureza das relações interpessoais, tende a ser remodelada à semelhança dos meios e objetos de consumo e segundo as linhas sugeridas pela síndrome consumista" (BAUMAN, 2009, p. 108).

A síndrome do consumo substitui valores como permanência pela transitoriedade e encurta o tempo entre o desejo e a realização do mesmo, aniquilando-o até o nível do impulso. O consumismo característico da vida líquida também reduziu o potencial de utilidade e de valor dos objetos consumidos, acelerando o processo de inutilidade, descarte e rejeição dos mesmos. O consumo é uma "questão de velocidade, excesso e desperdício". Apenas o lixo, acrescenta o autor, resultado de todo ato de consumo, é sólido e durável.

Numa sociedade de relações instáveis, sem garantias de alguma previsibilidade ou durabilidade, as referências possíveis para a ação são indicativos de consumo e a ação é uma ação de consumo. Em meio à incerteza, são as marcas de produtos, os logos, que indicam aos consumidores pontos de localização, podendo "guiá-los no caminho confusamente sinuoso e minado que leva à felicidade" (BAUMAN, 2009, p. 19). Tais elementos funcionam como sinalização de reconhecimento e aprovação pública, resgatando o consumidor perdido e conferindo-lhe signos de identidade. As grifes são os marcadores da identidade na vida líquida.

A construção da identidade (que, desde a Idade Moderna, deixou de ser uma "atribuição" para ser uma "realização") agora é entendida a partir de sua possibilidade de ser transformada constantemente. A noção sartreana de projeto de vida, como lembra Bauman (2009), tornou-se uma impossibilidade. A identidade na contemporaneidade só faz sentido como "atributo momentâneo": "precisa ser continuamente montada e desmontada. Cada uma dessas duas operações aparentemente contraditórias tem a mesma importância e tende a ser igualmente absorvente" (BAUMAN, 2009, p. 22). Todo o processo de remodelagem está incluído, evidentemente, na lógica do consumo. A própria identidade pode ser comprada, reprocessada e reciclada. No lugar do autoaperfeiçoamento, o consumidor prefere adquirir um novo self, "feito sob encomenda".

Diz-se do século XVIII que foi um dos momentos históricos em que o homem mais alterou sua aparência física, dissimulado debaixo de perucas, pó-dearroz, maquiagem e roupas com ênfase na decoração excessiva de fitas, babados, flores, amarrações. No entanto, toda alteração possível era ainda exterior. $\mathrm{Na}$ contemporaneidade, a identidade encontra meios de transformação não apenas exteriormente através do consumo de objetos, mas a partir da remodelagem do corpo $^{2}$ em si. O self novo, porém, é alterado em todas as direções, de fora para dentro, mas também de dentro para fora. Não só o corpo, modificado em ambas as direções, tem relevância na construção-reconstrução contínua da identidade. Os valores pessoais e desejos perseguidos pelo sujeito também são fornecidos mercadologicamente. Os padrões comportamentais e experiências emocionais fazem parte do grande "kit" identidade da sociedade de consumo.

Por isso, a vida líquida descrita por Bauman (2009) implica em perdição, pois a própria identidade é errante em função de sua impermanência física e valorativa. Assim é "(...) a arte da "vida líquida": aquiescência à desorientação, imunidade à vertigem, adaptação ao estado de tontura, tolerância à falta de itinerário e direção e à duração indefinida da viagem" (BAUMAN, 2009, p. 10). Sendo o estado de perdição a condição da existência contemporânea, a vida líquida é "precária" e tem por base a "incerteza constante". Diante da volatilidade dos princípios que regem a vida, a ordem possível é a de caráter aleatório, que antes gera a ilusão de segurança do que de fato serve como fundamento regulador.

$\mathrm{O}$ alfabeto em Matteo cumpre essa versão de arranjo organizador. $\mathrm{O}$ arranjo de base aleatória não chega a constituir um princípio ordenador, já que a ordenação implica uma ação de ordenar, fundada em critérios distintivos e classificatórios, que estão excluídos do modo randômico de gerar listas. O princípio aleatório de organização configura um método bastante superficial para o estabelecimento de um sistema classificatório. $\mathrm{Na}$ verdade, ele é insuficiente para classificar pois não cria categorias. Apenas diz respeito a uma organização de ordem espacial, uma disposição de elementos, sem a atribuição de valores.

Apesar de referir a uma sequência determinada, já estabelecida e convencionada, de letras, o alfabeto como fundamento ordenador é, portanto, instrumento instável justamente porque sua lógica reside na convenção aleatória, ficando exposto ao questionamento por arbitrariedade. O seu poder de ordenação é ilusório, não passa de mera enumeração. A ordem que rege o livro de Gonçalo Tavares é desordenada. Tão precária é a ordem

\footnotetext{
2 O corpo alterado articula-se a partir de possibilidades de transformação (1) orgânica, (2) tecnológica e, (3) simulada. Na primeira, inserem-se as remodelagens de partes do corpo e a ideia de replicação por meio do genoma; na segunda, todo tipo de extensão ou inserção de elementos tecnológicos que recuperam ou substituem partes no funcionamento do corpo; e, na terceira, está a recriação do corpo e da identidade no ambiente do ciberespaço. A segunda possibilidade de alteração do corpo, via tecnologia, abrange uma variedade de diferentes situações do corpo biônico e estende-se às previsões rumo ao corpo híbrido, nos termos de Lúcia Santaella (2003), "biocibernético", "entre orgânico e maquínico" - além das imaginações rumo à identidade completamente virtual, em novo suporte não corporal. A completa alteração da condição corporal reflete sobre o próprio sentido do corpo, obrigando a uma revisão de seu entendimento e, consequentemente, a uma reflexão sobre a identidade.
} 
alfabética, que o próprio posfácio, que a aponta como princípio ordenador, a subverte por meio da palinódia. $\mathrm{O}$ princípio ordenador é contrariado quando o texto recupera o seu sentido aleatório, desfazendo a lógica da ordem. Assim, experimentando trocar o ordem do alfabeto, toda sequência da narrativa seria inevitavelmente alterada, até eliminando possivelmente certas personagens.

Por esse viés, a ordem alfabética do livro é entendida como ordem exterior aos acontecimentos que ligam as personagens. O princípio ordenador alfabético do texto poderia inclusive ser substituído pela sequência numérica: "É como se existisse uma série de acontecimentos e, em vez de os contarmos $(1,2,3 \ldots)$, damos-lhes nomes. Os nomes das personagens são assim os nomes dos acontecimentos" (TAVARES, 2013, p. 155). O que está ligado são os eventos do mundo e não a ordem das letras. Colocada em xeque a ordem alfabética, o texto propõe a abertura para diversas possibilidades de combinações diferentes para as ligações entre as personagens, considerando que cada nova combinatória levaria a outra solução narrativa, com novos elos: "A ligação parece evidente, mas outra ligação qualquer também o poderia ser" (TAVARES, 2013, p. 156).

Por outro lado, o caráter de convenção do alfabeto, que o enfraquece como princípio ordenador da narrativa, também é funciona como tábua de salvação. A hierarquia do alfabeto pode ser o que separa o judeu do campo de extermínio, por exemplo, como aponta a reflexão ${ }^{3}$ do posfácio. Dessa forma, o aleatório assume forma "decisiva" e mesmo "trágica". Além disso, num contexto de desorientação, o aleatório convencionado como ordem é antídoto para a hesitação: "Em Matteo perdeu o emprego não há hesitações no itinerário da narrativa porque felizmente existe a ordem alfabética" (TAVARES, 2013, p. 112).

De fato, há outras combinatórias possíveis na relação entre as personagens que podem ser pensadas por tema (por exemplo a presença do lixo em episódios diferentes) ou por circunstâncias da ação, as quais geram o contato (por exemplo, Holzberg, que não tem ligação alfabética com Aaronson, liga-se a ele por ser o arquiteto da rótula; assim como vários personagens que se ligam alfabeticamente possuem também elos pela ação que desempenham e os

\footnotetext{
3 No diálogo com a tradição racional filosófica-teórica, evidenciado pela inserção reflexiva do posfácio, o tema do alfabeto como princípio ordenador remete à noção do próprio instrumento de classificação das coisas do mundo, ordenadas pela linguagem, como objeto do discurso. A abordagem do posfácio ficcionaliza a teoria, propondo a desconstrução da tradição discursiva científica, intensificada pelo debate contraditório acerca do elemento aleatório do alfabeto. Desvelando a origem convencionada da ordem da narrativa, a obra sugere o potencial questionamento de toda ordem estabelecida, que torna as coisas do mundo familiares ao pensamento. Portanto, o pensamento desfamiliarizase com o discurso que o constrói. Daí resulta, a necessidade e mesmo exclusividade de uma escrita errante.
}

coloca em contato com o personagem seguinte: Holzberg é amigo de Hornick e os dois encontram com Horowitz no labirinto). O que a ordem alfabética como eixo narrativo faz é determinar relações com ênfase no ponto de vista espacial e não temporal.

A narrativa de Gonçalo Tavares organiza-se espacialmente, remetendo (mais ou menos, como informa o posfácio) à figura da circunferência, mas, principalmente, a do labirinto. Encerrada a sequência das letras no $\mathrm{M}$, a narrativa, porém, não termina com Matteo e o aparecimento de Nedermeyer no episódio sobre a personagem do título joga a narrativa de volta ao começo, já que o nome de letra $\mathrm{N}$ aparece na primeira cena, quando o personagem assiste o atropelamento de Aaaronson, na letra A. O texto estrutura-se a partir de uma forma geométrica circular, presente na obra também como elemento diegético: na rótula em torno da qual corre sem rumo o personagem Aaronson e que foi projetada por Holzberg, aficcionado pelo círculo, que, no entanto, a faz quadrada. Como a rótula quadrada de Holzberg, a narrativa sobre Matteo apresenta um falseamento da forma circular (e de seu ponto final, que não é Matteo, mas Nedermeyer: a última personagem é afinal a penúltima). Trata-se, como esclarece a nota 30 do posfácio, de uma elipse.

Para além das observações a respeito da circunferência que o próprio livro propõe, é possível estabelecer uma relação do texto com a imagem do labirinto, o qual é igualmente referido diegeticamente - no episódio envolvendo o arquiteto Holzberg, o veterinário Hornick e o arqueólogo Horowitz - e "teoricamente", nas reflexões finais. Superando a organização alfabética, a narrativa repete, através da ligações entre os personagens, o emaranhado de entrecruzamentos que compõem o labirinto. Do mesmo modo que seus deslocamentos no espaço da narrativa, a ação dos personagens também apresenta aspecto labiríntico na medida em que envolvem comportamentos e atitudes "circulares", sem rumo, errantes. Cada personagem age em torno de suas obsessões, num movimento sem saída, em que o elo entre eles é tão frágil e aleatório quanto a ordem do alfabeto.

A ação dos personagens não têm resultado nenhum, não se desdobram ou evoluem em novas ações e transformações, encerram-se em si mesmas como os caminhos sem saída de um labirinto: “(...) o labirinto também é isso: uma infinidade de sem saídas. Não se vai a lado nenhum por muitos lados, ou: há muitos caminhos para não se ir a lado nenhum: eis o labirinto" (TAVARES, 2013, p. 135). A citação referida, numa construção sintática circular em que a frase inicia com a indicação de que irá conceituar o termo labirinto e termina com o advérbio que marca a apresentação do mesmo (começa e termina referindo o conceito), serve também como definição do comportamento dos personagens. Estes 
são dominados por obsessões que desencadeiam ações minúsculas em torno de detalhes absurdos: correr apenas em torno de uma rótula, lavar o lixo e tentar devolvêlo à cadeia de consumo recolocando-o nas prateleiras, colecionar baratas, acumular escândio, recolocar incessantemente uma bandeira no meio de uma clareira onde ela é substituída, não se sabe por quem, por outra diferente, limpar o automóvel como "transformação espiritual", etc.

Todos os personagens ao longo da narrativa estão envolvidos em ações mínimas, obsessivas, intermináveis e estúpidas. A tal ponto seus comportamentos são absurdos que o narrador sugere uma distinção entre a existência mecanizada e sem sentido que levam os personagens e o conceito de estar vivo. No episódio de Aaronson, personagem que começa a narrativa morto, o narrador abala a separação radical entre vivo e morto, tornando ambos os conceitos ambíguos por meio da ironia e do tempo verbal. A narrativa inicia assim: "Nem sempre Aaaronson esteve morto. Num certo período, Aaronson foi mesmo, sem exagero, um ser vivo" (TAVARES, 2013, p. 7). A morte invade a vida no sentido de que viver não significa necessariamente "estar vivo". O texto separa a ideia de estar vivo, que, na vida de Aaaronson, durou um "certo período", da obsessão que se segue: "Entre os vinte e sete e os trinta anos Aaaronson circulava - como um inseto obcecado - em torno de uma rotunda." (TAVARES, 2013, p. 7). A partir de seu comportamento compulsivo, Aaaronson animaliza-se, tornado inseto pelo narrador e finalmente ressurge monstruoso:

Qualquer hábito, qualquer repetição de um ato por mais absurdo que seja, rapidamente é absorvido: o excepcional transforma-se em poucas semanas; em certas circunstâncias bastam dias para que o monstruoso e o informe se faça normalidade e hábito. No limite: fato a que não se dá atenção, paisagem. (TAVARES, 2013, p. 7-8)

Além do espaço reflexivo do posfácio, o narrador inclui o pensamento teórico na parte narrativa, abordando, neste caso, o argumento acerca do grotesco que invade a vida dos personagens pela instauração do absurdo. O mais monstruoso é o monstro que se normatiza, que impõe a regra. São os personagens que adotam o absurdo como ação cotidiana com aparência de normalidade e são tantos os comportamentos descritos na narrativa que cada um assenta ordinariamente na paisagem urbana. É o narrador que, como se portasse lupa, aponta a incongruência das ações: "Poderemos falar de comportamentos maníacos precisos, embora não enquadráveis em nenhuma doença que os médicos dominem o suficiente para a domesticar com a suavidade aparente de um nome." (TAVARES, 2013, p. 15).
Volta-se assim à questão dos nomes, em ordem alfabética, para denominar as cenas mínimas que compõem a narrativa, descrevendo obsessões doentias. $\mathrm{O}$ monstruoso sem um nome permanece monstruoso. Por isso, o narrador escolhe (em vez da ordem numérica, por exemplo) para cada evento um nome; cada nome organizado conforme o alfabeto: são duas maneiras simultâneas de se aproximar do desconhecido, dando-lhe forma: nome e ordem: "Dar um nome humano a algo que acontece no mundo é uma das maneiras de humanizar o monstruoso e o informe que não entendemos." (TAVARES, 2013, p. 155).

O narrador faz, portanto, um esforço de compreensão de seus personagens-objetos, descritos de modo impessoal e sem empatia como no discurso científico ${ }^{4}$. Num movimento cíclico dentro da narrativa, os personagens monstruosos retornam à condição humana ou, pelo menos, pela nomeação, reaproximam-se dela em outras condições: doentios e maníacos. Os personagens parecem perdidos entre o estatuto de humanidade e a mecanização e/ou animalização das suas vidas na cidade. Por isso, eles vivem em estado de errância de si mesmos e a perdição é a condição de suas ações desprovidas de perspectiva, presas ao círculo, ao hábito, ao labirinto.

Entre as sete e as sete e meia, os automobilistas que por hábito passavam pela rotunda já sabiam que, também por hábito, um homem, vestido a rigor com calções e camisa de atleta, circulava por ali. Centenas e centenas de vezes em redor da mesma rotunda, como um carro que não soubesse o caminho, que hesitasse entre seguir por uma direção ou outra; que se deixasse estar por ali, à roda, não arriscando, não tomando uma opção. Enquanto estiver na rotunda não estou perdido, pelo menos não volto atrás. E eis um dos atrativos daquela circulação, circulação quase infinita não fora ela terminar com exatidão às trezentas voltas: em redor de uma rotunda ninguém volta atrás, ninguém se engana, ninguém tem de assumir o erro e fazer inversão da marcha. A vida, apesar de tudo, é fácil. Numa rotunda. (TAVARES, 2013, p. 8)

A permanência no círculo gera a impressão de não estar perdido. A repetição do hábito, mesmo monstruoso, e a adesão à convenção, mesmo aleatória, criam a sensação de sentido, mesmo no absurdo. Essa é a lógica que move

\footnotetext{
4 As séries (recurso de escrita recorrente na obra do autor) temáticas ou alfabéticas do livro, considerando que os personagens aglutinam-se entre si a partir de outras ordens que não a do alfabeto, além da série ficcional (sob forma de episódios ou micro-narrativas) e teórica (sob forma de notas numeradas), estabelecem ao logo da obra um jogo de oposições e contradições entre as formas discursivas diferentes referenciadas no texto. Com os elementos que buscam refamiliarizar o monstruoso, o texto reafirma os padrões discursivos científico-filosóficos, antes contrariados. Porém, faz uso de uma dicção científica como instrumento de reafirmação do absurdo e não do lógico, num jogo ininterrupto entre ordem e desordem.
} 
os personagens de Gonçalo Tavares, enredados em vidas minúsculas, perdidos no labirinto, esta "máquina de fazer miniaturas". Na nota de número 10 do posfácio, o texto oferece um "conselho" (além de reflexão teórica, a segunda parte do livro também aconselha, embaralhando mais uma vez as fronteiras discursivas) segundo o qual encontrar uma posição no mundo (pela "afasia diante do grande") se assemelha ao percurso no labirinto, remetendo ainda ao aspeto espacial que permeia a narrativa. Dessa forma, o texto afirma a relação do indivíduo com o mundo como uma forma de perdição, experiência labiríntica. Tal relação é pensada de uma perspectiva espacial, estabelecendo-se a partir de uma posição almejada: colocar-se no mundo, escolher e assumir uma posição, significa o percurso impossível do labirinto. Encontrar a posição exigiria descobrir e conhecer o itinerário no "desenho de louco" que é o labirinto.

No entanto, perder-se não é apenas etapa inevitável do processo e mesmo a descoberta da saída não é ainda sair: é pertencer à máquina. $\mathrm{O}$ tempo da incerteza é sempre incomparavelmente maior ao da descoberta de trajeto aberto. Feito de múltiplos caminhos, mas de apenas uma saída, o labirinto encerra uma ideia de violência na sua composição espacial. Associado à noção de mundo, o labirinto traduz a visão autoritária da saída única, de apenas uma solução possível.

E, como se existisse apenas uma verdade e uma solução no mundo, o labirinto funda essa coisa estranha que é a crença num único caminho; um processo violento: todos os caminhos estão barrados exceto um. (...)

Um labirinto tem, pois, a forma espacial de uma religião, de uma crença. No fundo, qualquer minotauro que se ponha ali só apressa a coisa, e apenas nos segreda que somos mortais. Somos mortais porque há minotauro que nos mata, portanto não podemos sentarnos à espera da solução: tens de ser crente mas a passo de corrida, eis o que o labirinto ocupado pelo bicho mau nos diz: reza para descobrires a única saída, mas reza como um corredor de 100 metros, reza enquanto corres à tua velocidade máxima. Se correres muito rápido, não precisarás de palavras santas - a corrida terminará antes do início da prece. (TAVARES, 2013, p. 135)

A violência do labirinto ainda vai além. Espaço da incerteza, ele, no entanto, não permite a hesitação. Sua infinidade de caminhos não são escolhas, mas ilusões de percurso. A semelhança do inquérito de Camer, o labirinto abre opções para que uma só, porém, seja adotada. Não há escolha. O questionário que Camer propõe a Boiman, que segue o louco Baumann, aquele que lava o lixo, tem a mesma função: retirar a possibilidade de escolha, oferecendo dois caminhos, sim ou não. Há apenas uma resposta, uma saída. O labirinto e o inquérito de Camer, com suas perguntas absurdas, eliminam o princípio da liberdade.

O problema é sempre este: és tu que estás na posse das perguntas - a minha liberdade é, pois, nula. Só posso responder. A idiotia comum é esta: a pessoa pensar que está livre porque pode responder, porque pode escolher. A grande diferença é esta: és obrigado a escolher: sim, não - e é essa obrigação que te rouba a liberdade mínima. Nem prefiro não, nem prefiro sim. Pelo contrário. (TAVARES, 2013, p. 129)

A existência, ou melhor: a crença, da única resposta elimina a liberdade da escolha, força a opção e não suporta a hesitação, quanto mais a interrogação. $\mathrm{Na}$ visão de fundo matemático, a decisão, a escolha, a saída única é uma obrigação. O dogma da solução única corrompe o fundamento da observação e da construção de conhecimento do mundo: a interrogação. É preciso, antes responder, afirmar, sim ou não, para cada caminho do labirinto e em alta velocidade. O labirinto com minotauro não comporta o tempo da hesitação. Apesar de perdido, o indivíduo não pode parar, não pode hesitar, não pode questionar. A tal ponto a lógica violenta do labirinto se impõe que hesitar passa a ser uma habilidade rara: "Hesitar sempre foi um projeto de vida para alguns. Ser capaz de continuar a hesitar até o fim, eis o difícil." (TAVARES, 2013, p. 111).

Para os que hesitam, desprovidos de "equipamento para a decisão", "para a prática desportiva da decisão" a referência só pode ser "negativa". Associada ao esporte, a decisão resulta, para os que decidem, na busca por "ganhar". Já os que hesitam estão ocupados em "redor de nada", sem tempo para ganhar. No primeiro caso, a decisão significa movimento rumo à ditadura da única saída; no segundo, a incerteza significa questionar, refletir sem, porém, avançar em termos espaciais. Não avançar significa uma forma de morte onde tudo que importa é alta velocidade, movimento. Quanto mais perdido, mais se corre "como se soubesse para onde vai".

No espaço de perdição, feito de caminhos barrados, só resta o movimento ou a hesitação excluída. É preciso ser crente e correr. $\mathrm{O}$ cético é uma possibilidade remota. Mesmo este precisa correr. Mantendo o movimento, o indivíduo circula por ilusões de caminhos possíveis, perdendo-se continuamente, mas crente na promessa de saída, inconsciente de pertencer à lógica da solução única. Ele crê na possibilidade de conhecer o itinerário ao longo da corrida e "ganhar". O movimento no labirinto de Gonçalo Tavares corresponde à velocidade e volatilidade da sociedade na vida líquida descrita por Z. Bauman, em que a "riqueza vem de um bem portátil: o conhecimento das leis do labirinto" (2009, p. 10). Os que praticam a vida líquida adaptaram-se ao estado de permanente desorientação, com 
base na crença da felicidade da saída. Vive-se na infinitude do movimento que não leva a lugar nenhum.

A referência dos adaptados à vertigem só não é negativa como a dos que hesitam porque "felizmente" existe o alfabeto. As convenções aleatórias fazem o papel de pontos de referência no labirinto. Como as grifes, marcas e logos que servem de localizadores na sociedade de consumo, o aleatório estabelecido como ordem fornece a tábua de salvação pela crença no ilusório. Desde que o movimento não pare e a velocidade aumente tem-se a impressão de escapar do minotauro, camuflando o perigo da máquina do labirinto em si, a qual reproduz incessantemente as suas "miniaturas".

Como um grande labirinto de escolha única e que ainda abriga um monstro em seu interior, a cidade é espaço de perdição e de loucura, onde os personagens exercitam seus atos maníacos. Perdidos, eles se entrecruzam numa metrópole qualquer. A cidade não tem marcas culturais nacionais, é qualquer lugar do mundo. A ausência de Portugal (e de portugueses, aliás) não exclui, porém, a reflexão acerca da identidade: esta é pensada num outro nível, a partir da condição individual, abrangendo um cenário coletivo, mas de uma coletividade global. Os personagens em Matteo expressam o sentimento de uma identidade coletiva doentia, louca e cega de experiências individuais maníacas e de isolamento.

Na cidade onde Matteo perdeu o emprego, o ambiente é claustrofóbico, feito de becos sem saída, de rótulas em que os personagens giram em torno de nada. A cidade labiríntica existe no limiar da razão, onde a "lâmina do mundo" tende a ferir a sanidade. Personagens beiram, ou alcançam de vez, o lado de lá da loucura. Mas é uma loucura, às vezes, mais sensata do que a normalidade, apenas desorientada nos seus métodos (caso, talvez, de Baumann). Os próprios limites entre razão e loucura não são fáceis de apontar, pois embaralham-se o tempo todo. Os atos ligados à normalidade cotidiana podem facilmente sofrer metamorfose, tornando-se absurdos (como correr apenas em torno de uma rótula, onde a fumaça, o metal e os carros dominam).

Os comportamentos dos personagens variam da normalidade ao absurdo e vice-versa. Há casos em que o gesto é absurdo, mas a ideia não necessariamente: como a preocupação de Baumann com o lixo, que desemboca no ato obsessivo e doentio de lavar e recolocar embalagens tiradas do lixo. No viés normalidade-absurdo, estão Aaronson (praticar a corrida é uma normalidade, mas compulsivamente em torno da rótula é absurdo) e Ashley (lava o carro compulsivamente também), por exemplo. Na linha absurdo-normalidade estão Helsel (colecionador de baratas), Koen (fixa repetidamente a bandeira na clareira, a qual é constantemente substituída) e Glasser (com a bateria do coração no carrinho de mão), por exemplo.
Na primeira situação, em que a metamorfose acontece do normal ao absurdo, há uma questão de excesso que transforma ações cotidianas normais em verdadeiras obsessões ridículas e absurdas. Na metamorfose do absurdo em normal, tem-se o fator repetição como meio de integrar o absurdo no contexto cotidiano, convertendo-o em hábito e, portanto, em coisa comum ou, pelo menos, em coisa com a aparência de normalidade. O hábito cria a ilusão da normalidade. Do mesmo modo, o excesso que modifica a normalidade para absurdo fazendo-o revela uma certa absurdidade no normal. Estabelece-se, entre o normal e o absurdo, uma relação circular em que o hábito está longe de fixar conhecimentos e apenas significa redundância e desordem.

A cidade labiríntica dialoga intensamente com a forma do círculo porque sua constituição demanda a repetição e o excesso. Assim são as ações na cidade, repetitivas e frequentemente excessivas. O espaço urbano funciona pela repetição de tudo, todos os dias e isso gera excesso. A cidade-labirinto não chega a se mostrar como uma distopia clássica, mas certamente minimiza as utopias, também ela é máquina de fazer miniaturas. Dessa forma, o cego Goldstein, por exemplo, sonha com milhares de gramas de escândio, a sua obsessão: “A utopia de Goldstein: que no seu caixão pudesse ir tanta quantidade de escândio como a que existia no resto do mundo" (TAVARES, 2013, p. 46). O elemento utópico é reduzido a imagens medíocres de ideal, acompanhando a ação mínima dos personagens.

Seguindo o raciocínio de Z. Baumann (2009), se o ideal utópico é substituído pelos bens de consumo, o "grande", o "enorme" de que fala o posfácio de Tavares não se sustenta e as "coisas pequenas" não ficam às "nossas costas", mas sempre bem em frente. No labirinto, lugar da tensão entre a obrigação da escolha e a constante hesitação, o ideal é minimizado, cedendo para a angústia da desorientação e necessidade de movimento. A utopia colocada à frente, como lugar a alcançar perde sentido num cenário em que avançar não significa sair do lugar. pelo contrário, avançar, na vida líquida do labirinto, significa permanecer. Deseja-se permanecer no jogo. Deseja-se não sucumbir na busca da saída única, crentes da saída única, pois não é possível enxergar por sobre os limites do labirinto.

Como um maluco que anda em redor de uma circunferência: ao mesmo tempo que avança, recua. Está avançando para o ponto de partida, está recuando para o destino - eis-nos, enquanto seres vivos: coisas desnorteadas, embriagadas, tentadas pelo caminho e não pela parte alta do mundo (olhamos em frente e por isso ficamos com essa cegueira parcial). Estamos loucos (...). Ficamos loucos com o tédio, mas também por um excesso de perguntas. (TAVARES, 2013, p. 109) 
A cidade é o espaço do absurdo: o lugar onde personagens doentios existem para suas obsessões. Cada um está preso à sua ordem aleatória individual e eles se relacionam entre si, no espaço urbano, de forma randômica. A cidade separa através de seus múltiplos caminhos e rótulas. Os personagens vivem antes de mais nada em situação de isolamento: sem elos afetivos, intelectuais, sem empatias. $\mathrm{O}$ acaso une os personagens. As suas posições aleatórias na cidade é o que os une. A narrativa acontece a partir dessas ligações randômicas (por isso o texto do posfácio esclarece que sua ordem poderia ser outra e, sendo sua ordem outra, outras personagens poderiam compor os enredos).

A ligação entre um personagem e outro e, portanto, entre um episódio e outro acontece pela posição que ocupam no espaço da cena. Nedermeyer está na janela quando Aaaronson é atropelado por Ashley que passava na rótula... ${ }^{5}$ e assim por diante até Matteo e, finalmente, Nedermeyer. Além de sua posição espacial (e simultaneidade de sua presença no espaço), o que une os

\footnotetext{
5 Uma sequência possível para a narrativa, seguindo a ordem alafabética é: Na letra A, o sujeito que corre repetidamente em torno da rótula, Aaaronson, é visto por Nerdermeyer da janela de um prédio quando é atropelado pelo sujeito que limpa o carro compulsivamente, Ashley, o qual precisa entregar uma encomenda, numa rua impossível, para Baumann, que é procurado, portanto, por Ashley e segue Boiman, obcecado em lavar o lixo e entrevistado por Camer, que lhe propõe uma pergunta sobre Cohen, professor de Letras cheio de tiques que encontra na escrita um modo de "fugir do corpo" e que é convidado para uma visita pelo professor que vive em Londres Diamond, o qual resiste com sua turma de alunos dentro de uma sala de aula invadida pelo lixo, tendo sido professor de Einhorn, dono de um bordel frequentado por Glasser, que leva a bateria do seu coração num carrinho de mão para encontrar a prostituta Goldberg, que também tem por cliente o cego Goldstein, milionário que compra escândio e é amante de Gottlieb, prostituto com tabela periódica em braille tatutada nas costas, que mata Greenberg e é afivelado na cadeira elétrica por Greenfield (Gottlieb é uma bifurcação na sequência narrativa, estando ligadao a dois outros personagens de forma direta pelo alfabeto; os demais se relacionam, fora da ordem alfabética por temas ou recorrência de imagens e ideias), que trabalhou também num laboratório com Helsel, diretor do laboratório que investiga uma vacina e gosta de colecionar baratas, além de ser amigo de Holzberg, o arquiteto da rótula quadrada aficcionado pela forma circular amigo de Hornick com quem entra no labirinto e encontra Horowitz, amigo de Indictor, que viu Kashine escrever "não", ato que atingiu Kessler, provocando seu divórcio da mulher, e que acabou num barco com Klein, seu assassino, o qual foi internado num hospício pelo dr. Koen, apaixonado por clareiras, fixando numa a sua bandeira, a qual é substituída por outra pela sua mulher Levy que, finalmente, é amiga de Matteo, que perdeu o emprego e fez contrato com uma mulher sem braços, além de encontrar Nedermeyer na feira, vendendo fotos, no dia em que Aaronson foi atropelado. No entanto, diferentes séries de relações entre os personagens são igualmente possíveis. Por exemplo, pode-se relacionar personagens pela (1) temática lixo: Baumann, Diamond, Helsel; pela (2) imagem do labirinto: Holzberg, Hornick, Horowitz e Indictor e, estendendo a imagem do labirinto de modo metafórico, incluir os demais; pela (3) ideia-imagem do círculo: Aaaronson, Ashley, Holzberg, Baumann, Koen; pela (4) ideia de loucura: Kessler, Klein, Koen, Baumann, sendo possível estender o conceito a vários outros personagens que não chegam a ser denominados loucos pelo narrador, mas que no posfácio são referidos como tal de forma generalizada ("estamos todos loucos"); etc. De modo que as possibilidades de novas coleções de comportamentos vão à infinitude, permutando-se o critério de relação entre os personagens. Ao mesmo tempo a abertura para múltiplas alternativas igualmente possíveis de relações esvazia a qualidade de classificação de qualquer critério que
} se escolha, restando apenas o aleatório alfabeto. personagens são suas obsessões, as quais, muitas vezes, remetem à temáticas que se repetem ao longo do livro. Assim, por exemplo, o professor Diamond, que resiste com sua turma em meio ao lixo, liga-se a Baumann, que lava embalagens, e também a Helsel, que desiste da coleção de baratas, juntando uma pilha de cadáveres de insetos, pelo tema do lixo presente nos três episódios. Baumann, por sua vez, liga-se a Kessler e Klein, os dois sensatos no barco da razão, e ao dr. Koen pelo tema da loucura. Da mesma forma, o arquiteto Holzberg se liga, pela presença da imagem do círculo, a Aaronson e Ashley e Bauman, em que o círculo reaparece como metáfora do ciclo que ele tenta refazer com o lixo.

Muitas conexões, portanto, entre os episódios e os personagens são possíveis com base em outros critério que não o alfabético, gerando um... mapa: das trajetórias dos personagens na cidade. Na cartografia possível da cidade-labirinto, não existem pontos de referência a não ser aqueles que podem ser criados pelo texto. A escrita é o único mapa possível ou antes o exercício de mapeamento. Por isso, a escrita de Gonçalo Tavares é a escrita da errância: "Escrevo porque perdi o mapa", costuma dizer o autor em entrevistas.

Ao contrário da possibilidade de acertar muito da matemática, ele diz ter escolhido a possibilidade de errar muito, nessa "caminhada mais ou menos sem meta" que é o espaço da escrita. A escrita errante busca seus pontos de referência criando-os. Faz isso através principalmente da recuperação e diálogo de ideias com figuras importantes da tradição literária e filosófica ocidental pela sua inserção no texto sob forma de personagens como acontece em várias obras do autor. Além disso, ele explora o aspecto espacial da configuração do próprio texto como faz em Matteo, recorrendo ao desenho geométrico do círculo e ("esquizofrênico") do labirinto.

O texto é espacializado geometricamente e as relações entre os personagens se dão sob a forma de rede, em que diversas conexões diferentes são possíveis, subvertendo a ordem alfabética que (aparentemente e aleatoriamente) rege o texto. A escrita remete ao esforço de mapear, de entender e conhecer o mundo e o humano em suas incongruências. Em Matteo, o texto busca fazer o mapeamento dos comportamentos absurdos que existem no espaço da cidade-labirinto. Outro tipo de conexão possível, decorrente da alfabética, é pensar a relação dos personagens como uma grande lista de comportamentos. O narrador usa uma linguagem impessoal, direta e desprovida de juízos, porém, com apontamentos teóricos, aproximando-se do discurso científico. A narrativa, de outro lado, tematiza a questão da aquisição do conhecimento por meio da imitação dos métodos e do discurso científico, apresentando inclusive uma taxonomia dos tiques do professor Cohen, além 
de uma série de situações com personagens da área das ciências.

O mapa textual dos personagens apresenta uma relação de tipos de obsessões. Trata-se de uma lista descritiva das "doenças" não conhecidas e, por isso, ainda "não enquadráveis" pelos médicos. Trata-se de uma lista que, segundo informa o posfácio, é criada a partir de nomes: Aaronson, Ashley, etc. O texto, portanto, nomeia os eventos doentios e os organiza em forma de lista, adquirindo aspecto acumulativo da enumeração. $\mathrm{O}$ livro é um catálogo de obsessões urbanas. Classificado alfabeticamente, em forma de lista, o catálogo apresenta a descrição e (às vezes, teorização) das manias doentias, loucuras e comportamentos estranhos de cada indivíduo-caso.

Mas a cidade não é apenas o lugar onde o absurdo acontece. É ela mesma espaço absurdo. A cidade é constituída, na narrativa, como espaço monstruoso, de forma impossível: disforme. O seu aspecto labiríntico gera movimento absurdo em que os caminhos não levam a lugar nenhum, nem de volta ao mesmo lugar (não sendo exatamente círculo). De rótulas quadradas, círculos que impedem o avanço, labirintos de caminhos barrados, placas redundantes, a cidade não faz sentido. É o que comprova Ashley ao tentar entregar a encomenda do sr. Baumann, no segundo andar do $\mathrm{n}^{\circ} 217$ de uma rua da cidade:

(...) aquela senhora não era o Sr. Baumann, por isso Ashley, depois de se despedir educadamente, desceu as escadas e já de novo na rua olhou outra vez para o número do prédio. Sem dúvida: o no 217.

Algo falhara naquela encomenda. Ashley, um pouco perdido, sem saber o que fazer, foi avançando ao longo da rua. (...)

Avançou mais um pouco (...) de repente levantou a cabeça e, por instinto, fixou-se, sobressaltado, no número do prédio que estava à sua frente. Era o $\mathrm{n}^{\circ}$ 217. Parou. De imediato, umas passadas largas, quase em corrida para o lado esquerdo, na direção de onde viera. Um prédio, ao lado de outro e de outro. Todos com o número 217. (TAVARES, 2013, p. 13-14)

Mesmo o número, que, como o alfabeto, oferece uma forma convencional de ordenar racionalmente determinado conjunto de informações, não gera significado na cidade-labirinto. A cidade aparece como espaço monstruoso não classificável, desfamiliarizado. O espaço passa por um processo de "desrealização" (BRANDÃO, 2013). O absurdo toma conta corrompendo os elementos de ordenação. A monstruosidade do espaço urbano não se restringe ao lugar, mas avança e se apega ao seres que ali habitam, ao mesmo tempo invadindo-os e revelando o monstruoso no humano.
O espaço monstruoso da cidade tem efeito sobre os habitantes e é também resultado de suas ações. Espaço e personagens são mutuamente causa e efeito, retomando o aspecto circular do texto. $\mathrm{O}$ monstro habita o espaço monstruoso e o espaço monstruoso faz o monstro: a máquina de miniaturas que é o labirinto. Na cidade, prolifera o efeito espiral (em curvas e ascendente) do labirintismo, em que as ações mínimas e absurdas dos personagens correspondem à configuração monstruosa labiríntica do espaço urbano. Através do labirintismo dominante a condição da existência é a desorientação. A perdição passa a ser permanente e não apenas fase no processo de achar. O labirintismo significa viver em estado de errância, no qual só resta o movimento acima de tudo, acima até do sentido: "Nada de nada: pensamos em pleno movimento; pensar enquanto se correr, pensar para poder correr" (p. 109).

No labirintismo, o movimento supera o pensamento porque o subordina ao seu princípio andante: "pensar para correr" e não o contrário. Incessante e aleatório, o movimento não produz sentido e impossibilita os meios que o fazem. Este tipo de movimento corresponde também a um tipo de obsessão e toda ação obsessiva se encerra em si mesma, circular, desprovida de potencial criador e transformador. A narrativa acrescenta ao movimento obsessivo, o itinerário vazio de referências que produz a errância e a impossibilidade do "colocar-se no mundo", do entendimento da própria posição. A cidade é também sem marcas culturais que a identifiquem; é qualquer cidade, todas e nenhuma. A errância, no entanto, representa, nesse contexto, a resistência contra a máquina de miniaturas. A errância é o que resta no espaço labiríntico em que o acerto é um engano, uma ilusão: é transformar-se em objeto da máquina.

Os personagens do livro de Gonçalo Tavares parecem adaptados à vertigem. Eles existem inconscientes de sua perdição. O narrador é que hesita e questiona, apontando as suas normalidades como absurdos. Por isso, sua escrita é errante: ele busca conhecer, inventariando absurdos. É uma escrita investigativa e experimental que se faz à deriva de gêneros e formas. O processo de escrever (que implica antes em ler) é espaço de errância, de procura e de descoberta e também de perdição: é processo. A escrita estabelece as referências (literárias e filosóficas). A cartografia possível só é possível na escrita com suas desestabilizações das fronteiras. Em lugar dos movimentos aleatórios do corpo que se desloca na cidade monstruosa, a escrita propõe o movimento do pensamento, propõe a espacialidade do pensamento com seus modos de operação (BRANDÃO, 2013).

O itinerário é construído (desconstruído e reconstruído) no processo de escrever, que é o mesmo que mapear: é refazer o mapa. É uma cartografia de lugar 
nenhum, mas do espaço da ideia. Este mapear lugar nenhum é a tentativa de ver a si mesmo e sua posição, é dar-se posição. O mapa recriado revela então mais do que os lugares, mostra o ser. A escrita é o espaço da utopia.

\section{Referências}

BAUMAN, Zygmunt. Vida líquida. Tradução de Carlos Alberto Medeiros. 2. ed. Rio de Janeiro: Zahar, 2009.

BAUMAN, Zygmunt. Amor líquido: sobre a fragilidade dos laços humanos. Tradução de Carlos Alberto Medeiros. Rio de Janeiro: Zahar, 2004.
BAUMAN, Zygmunt. A arte da vida. Tradução de Carlos Alberto Medeiros. Rio de Janeiro: Zahar, 2009.

BRANDÃO, Luis Alberto. Teorias do espaço literário. São Paulo: Perspectiva; Belo Horizonte: FAPEMIG, 2013. (Estudos, 314).

TAVARES, Gonçalo Manuel. Matteo perdeu o emprego. Rio de Janeiro: Foz, 2013.
Recebido: 18 de abril 2014 Aprovado: 15 de setembro 2014 Contato: isadora13d@gmail.com 